\title{
The Carpets and Karma: The Resilient Story of the Tibetan Community in Two Settlements in India and Nepal
}

Dr. Venkat Pulla ${ }^{+*}$ and Kanchan Prasad Kharel ${ }^{\bar{I}}$

\section{Abstract}

This paper is about the Tibetan people in two settlements, mainly in Nepal and India. Tibetan refugees started crossing the Himalayan range in April 1959, in the wake of the Dalai Lama's flight into exile and landed mostly in Nepal and India. Tibetans around the world do not know their future nor do they appear unduly worried. Most of them appear resilient and hopeful to see a 'free Tibet' a dream closer to their hearts, someday in the future. In this paper, we delve at their deep association between their philosophy of life based on the principles of 'karma' and their everyday economic avocation of weaving 'carpets'. We find that these people weave their lives around karma and the carpets. Karma embodies their philosophical and spiritual outlook while carpets, mats and paintings symbolise their day-to-day struggles, enterprises to cope, survive, thrive and flourish. The 'karma carpet' symbolises their journey into the future. The Tibetans although a refugee group do not have the same rights and privileges comparable to other refugees living in the world decreed under the United Nations Conventions. In this paper, we present the socio-economic situation of these refugees, their enterprise and their work ethic that makes them who they are in the Nepalese and in Indian societies. For this research, we have triangulated both desk studies and personal narratives from focus groups and interviews to present a discussion centred on the Tibetan struggle for human rights and their entrepreneurship through the carpet industry mainly in Nepal and India.

Key words: Tibetan refugees, carpet, karma, Tibetan resilience, Nepal, India

\footnotetext{
* Corresponding Author

${ }^{+}$Senior Lecturer, the School Social Sciences, University of the Sunshine Coast, Maroochydore, Qld, 4558, Australia. Emails: dr.venkat.pulla@gmail.com and vpulla@usc.edu.au; ${ }^{\bar{I}}$ Masters in Development Studies at Kathmandu University, Kathmandu, Nepal. Email: kanchan@yuwa.org.np

(c) 2014 Pulla and Kharel. This is an Open Access article distributed under the terms of the Creative Commons Attribution License (http://creativecommons.org/licenses/by/2.0), which permits unrestricted use, distribution, and reproduction in any medium, provided the original work is properly cited.
} 


\section{Introduction}

In recent times, the young Tibetan monks have sadly self-immolated themselves raising alarm about human rights and the Nepalese response has been described as being evenly heavyhanded. This response from the Nepalese government appears to be derived from selfinterest and self-preservation that comes with a price of compromise with China.

The news of the young Tibetan monk, Drupchen Tsering, who self-immolated himself in Boudhhanath, Kathmandu, on 13 February 2013, recently ignited the long suppressed issues of the Tibetan refugees in Nepal (Republica, 2013). The event drew attention of the national and international political and nonpolitical actors. Tibetan official agencies kept on demanding the body for commemorating the last rituals according to the Buddhist tradition. However, the body was kept for 41 days in mortuary, and was declared 'unclaimed' by the Nepalese Government on 25 March 2013. Following this, his mortal remains were cremated in Pashupati Aryaghat, the cremation grounds. Only handful of human rights activists' Kharel, Sivakoti and Bandi defied the act of Nepalese government and expressed serious concern about the Tibetan people's rights to practice their culture, tradition and religion.

On 15 April 2013, International Herald Tribune, the global edition of New York Times, published an article titled 'China curbs flow of Tibetans into Nepal' by Edward Wong. It mentioned the active role of China in subjugating the Tibetan refugees living in Nepal by supporting the Nepalese government through deliberate yet subtle means of assistance to various development projects through financial assistance (Wong, 2013). The report explicitly mentioned that Chinese officials were curtailing the flow of Tibetan refugees in Nepal-China borders and have been creating influence over Nepalese government in suppressing Tibetan refugees' anti-China activities.

Previous incident of self-immolation was one of a 16-year-old Tibetan girl residing in the village of Dageri in China's northwest province of Qinghai. This occurred coincidently on the 64th
International Human Rights Day (Republica, 2012). While security failed in stopping such acts in China, Nepalese police forces, on the contrary, intensified its security systems in major places in Kathmandu-Bouddha and the Thapathali Bridge area where most Tibetan refugees reside. Thapathali Bridge connects Kathmandu and Lalitpur district. The Bouddha is the historical and religious place outside Ring-road in Kathmandu where majority of Nepalese Buddhist people live and preach the teachings of Buddha. The Tibetan refugees live in this place mainly for two reasons: first, there is a Tibetan refugee camp nearby Bouddha area; second, Tibetan refugees are coreligionists to Nepalese Buddhist communities like Lama, Tamang and Sherpa. This location is also the main entrance to reach the National Human Rights Commission (NHRC), Nepal, which is located at Pulchowk, Lalitpur, and barely a few metres away from the bridge, and the NHRC. A young human rights activist belonging to a Hyolmo community of Helambu region of Nepal has the following to say:

Early morning of that day, I was on my way from Bouddha to NHRC. That day human rights community of Nepal gathered to mark 64th International Human Rights Day and to celebrate Human Rights jointly organised by coalition of human rights organisations working in Nepal. However, I was stopped three times by the Nepali police, near Bouddha, Pulchowk Bridge and few meters in front of the NHRC. I had a tough time while convincing them about my identity as a Nepali citizen and not a Tibetan refugee. I repeatedly showed them my ID card. I struggled because my physical appearance is similar to the Tibetan people and also I am a Buddhist. In addition, because many Tibetans have long been hiding in Nepal with Nepali citizenship changing their surname as Hyolmo, Tamang and Lama, at present, there is a level of suspicion growing towards original Nepali citizens like me. Moreover, we Hyolmo people are Buddhists. 
Another human rights activists working closely with the Tibetan community in Nepal narrated as follows:

On that day, many Tibetan people were forcefully held in custody at Bouddha Police Station without reason possibly to curb the possible anti-Chinese protests that Tibetan people might lead to.... Such actions from Nepalese government clearly indicate that the Government in Nepal does not concern itself with the rights of Tibetan refugees nor is committed to their freedom of opinion, expression and peaceful congregations.

The aforementioned narratives thus provide the Tibetan refugees and its effects on their communities' conditions of living in exile. Clearly, the Tibetans do not have any means to retaliate against China but to continue to cope, survive, nurture resilience and hope for freeTibet, while facing strict measures from the Nepalese government. Hence, the key purpose of this research is to present the socioeconomic situation of the Tibetan refugees, their enterprise and their work ethic that makes them who they are in the Nepalese society. Alongside, it also highlights the socioeconomic condition of the Tibetan refugees taking refuge in India.

We begin with a brief description of the methodological approach deployed to gather data for the research. Following this, we provide a brief historical review of the Tibetan question. For Tibetans, the 'karma carpet' symbolises their journey into the future. Hence, in this research we delve at their deep association between their philosophy of life based on the principles of 'karma' and their everyday economic avocation of weaving 'carpets'.

\section{Methodology}

We conducted three focus group discussions and interviews with young people addressing three important questions: what does independence, democracy and human rights mean for the young Tibetan people living in
Nepal? How do the Tibetan people maintain their livelihoods? How do they internalise the understanding of 'Karma' and 'suffering'? These three questions are put forward in this research with an aim to appreciate their political, economic and spiritual mindset with a view to describe their source for 'resilience' and their 'hopes' for the unknown future. These focus groups and interviews were conducted in November 2012. We had no preconceived logically deduced hypothesis and in our sampling too, we did not aim for population representation but for the possibility of finding some answers to our questions that may allow us to move towards some theoretical understanding. The first author has been researching in coping and resilience in the last few years and a collection of research-based papers was released in 2013. Although five intensive interviews were conducted, we have excerpted only relevant experiences that could be included in this paper.

We hypothesise that the Tibetan people weave their lives through 'Karma' and 'Carpets', where 'Karma' embodies their philosophical and spiritual stance while carpets, mats and paintings symbolise their day to day struggles, economic enterprises to cope, survive, thrive and flourish. Thus, we are using the 'karma carpet' as a binomial expression for Tibetan people to symbolise their journey into the future. Additionally, we have triangulated both desk studies and narratives acquired through focus groups, interviews, observation and authors' experience to present the foregoing analysis and discussion.

If people of ethnic origin are denied the privileges to enjoy, develop and transmit their culture and language, whether collectively or individually, we surmise this to be a violation of human rights and, in particular, the right of ethnic groups to behold their practice and respect for their cultural identity. Grave or extreme forms of massive violation of human rights presuppose intent, which can be inferred to from the nature of the acts as denial of the rights to the community to offer the last rites to the monk who gave his life for the Tibetan 
cause. The year 1989 when the Maoist insurgency surfaced in Nepal, it was amply clear that it had tacit support and approval from China and the Tibetan refugees could see a less humane approach by the government of Nepal towards them. The regimes before had seen the Tibetan refugees as being reasonably accepted, both in terms of recognition and facilities that they were able to access in this country of their asylum. Therefore, in the next section, we discuss a brief history of the Tibetan people; and then present the one China policy of the People's Republic of China (PRC) and its implications to Tibetan communities. Hence, as stated above, the key objective of the paper is to bring out the strong connection of Karma, the spiritual repository within the community, and their livelihoods on one hand and on the other hand, their everyday coping strategies with the realities of a refugee with limited or no privileges at all and building their resilient lives and not giving up hope for a free Tibet. A significant amount of research narratives enrich the discussion presented in this paper. Although not re-presented through the narratives of the respondents, the guiding definition of resilience that we have utilised as part of our theoretical framework is to relate resilience to the way in which people confront and deal with those stressors that one encounters throughout the lifespan, creating positive meaning and maintaining function (Bonnano, 2004:20). Resilience is constructed using coping strategies, which refer to those actions that people indulge in to alleviate, tolerate, and accept or minimise stressors that present (Pulla, 2013: b). Undeniably, for the Tibetans these stressors are many. They include religious persecution, eviction from homeland, separation from family, violence and poverty, forced adaptation to new cultures, challenges to identity and many more. Invariably, the Tibetans will have utilised a range of coping mechanisms and strategies in order to survive these stressors and by the very fact that their existence is continuing, with what appears to be a success, one can assume that some measure of resilience has been established from these strategies.

\section{Brief History of the Tibetan People}

In the year 1950, Mao's Red Army controlled the territory of Tibet by defeating Tibetan army. Nine years after, in 1959, Tibetans declared the Guerrilla War against Chinese troops. Ganguly (2001) notes that while the Chinese brutally suppressed the uprising, the Dalai Lama and his ministers fled across the Himalayas, to India. In this process, several thousand refugees also migrated to the Kingdom of Nepal.

In terms of Nepal-Tibet relationship, Nepalese historical annals confirm that Nepal's relations with Tibet has always been positive and were further strengthened in 639 AD when Nepalese King Amsu Verma gave his daughter Princess Vrikuti to the ruler of Tibet Strong-Tsam Gampo in marriage (Hamal, 2010).

In relation to Indo- Tibetan relationship, India certainly helped facilitate the temporary settlement of the first Tibetans through favourable domestic legislation that regulated entry of Tibetan nationals into India and allowed them to obtain a certificate of registration since December 1950. India also helped with the logistics of transit camps on the border and gave land to the refugees. In fact, it could be argued that India has gone out of its way to accommodate Tibetan refugees. Nepal has been a Tibetan refugees' destination ever since 1959 as it became a home to about 12,000 refugees who were mainly settled at camps at Jawalakhel in the Kathmandu valley, Chialsa in Solukhumbu district, Pokhara in the mid-west and at several smaller centres in the far West. The Tibetan communities and human rights activists believe that there could be at least 12 refugee camps in different parts of Nepal, which may not have been known to Nepalese authorities. However, no proper records are available which tells how many Tibetan refugees actually live in Nepal at present. References from random sources like newspapers and websites suggest that there are around 15000 Tibetan refugees residing in Nepal. According to the latest demographic survey conducted by the Tibetan Governmentin-Exile, which came out in November 2010, 
there are 94,203 Tibetans in India, out of the 127,935 Tibetans who live outside (Bentz, 2012).

The Nepalese Government and the International Red Cross, Swiss Red Cross, the United Nations Human Rights Commission for Refugees (UNHCR), the Tibetan Refugee Aid Society of Canada provided opportunities to begin their new life in camps. The introduction of carpet-weaving cottage industries within the Tibetan camps in Kathmandu and Pokhara and in McLeod Ganj, Dharmshala and Majnu Ka Tilla in Delhi are milestones in the economic development of the Tibetan people. O'Neill (2005: 277) affirms the support of Swiss Aid and Technical Assistance (SATA) which "proposed that the refugees set up carpet weaving cottage industries in each of these camps to provide employment and an income". The reason why Swiss donors invested in Carpet industry is because of the traditional specialisation and sophistication that the Tibetan people had attained in carpet weaving. The carpet tradition appeared to have been running in their sinews and in their blood, something they handed over from one generation to the next since ages. The carpet industry led by the Tibetan community not only supported the livelihood of Tibetan exile community but also became one of the leading export industries of Nepal and made the government and Nepal private enterprise rich in its own way. Several Tibetans during those days were also allowed to obtain citizenship of Nepal so that they could own carpet companies and factories. The offering of naturalised citizenship to Tibetans by the Government of Nepal in 1970s meant "that naturalized Tibetans in Nepal could legally export goods across the border, and own property in Nepal" (O'Neill, 2005: 282). Such facilities made Tibetans economically stronger and many of them became even wealthier than the local Nepalese. Tibetan children went to better schools and their livelihood condition changed drastically.

In India, in addition to McLeod Ganj in Dharmshala, the Majnu Ka Tilla in Delhi is rather unique Tibetan refugee camps. They are completely self-sustaining, are a tribute to the hard work and obstinate refusal to be daunted, and overwhelmed by the grinding poverty within the camp and in the surrounding areas. While Dharmshala is considered the heart of the Tibetan world, places like McLeod Ganj and Majnu Ka Tilla are commercial hubs of this exiled community.

\section{The One China Policy}

Since the Maoist insurgency in 1989 in Nepal, the situation changed for the Tibetan refugees. Chinese government entered into the scene and Nepalese government had no choice other than to follow the Mandarins of the Chinese Government. The Nepalese government commenced the process of non-recognition to Tibetan refugees who arrived in the country after 1989, which meant neither special status nor any civic privileges at par with the previous refugees. Even distributions of refugee's cards were stopped. This shifted in the asylum preference of the Tibetan refugees and Nepal became a transit point more than the final destination. Dharmshala in India became the final destination where Dalai Lama and Tibetan government in exile were located. Furthermore, after China heightened security along its border and increased restrictions on internal freedom of movement in 2008, the number of Tibetans who transited into Nepal has also dropped significantly (United States Department of State, Bureau of Democracy, Human Rights and Labour).

More recently, two prominent diplomats Bhek Bahadur Thapa and Kedar Bhakta Shrestha separately answered the question about the foundations of diplomatic relationship between Nepal and China and those that affect issues of Tibetan population in Nepal, at Kathmandu University symposium on 2 May and 9 May 2013. They emphasised the reasons to be Nepal's adherence to 'Principles of Panchasheel' and the acceptance of Nepal to 'One-China Policy'. Nepal-China relation is based upon the foundations enshrined in the five principles under Panchasheel, which regards respect for each other's sovereignty 
and territorial integrity; non-aggression; noninterference in each other's political, economic and ideological affairs; peaceful coexistence, equality and mutual benefit (Aryal et al. 2010, Hamal, 2010). Likewise, under 'One-China' Policy, China would consider Nepal as equal nation and does not reserve any intention to influence internal affairs of Nepal. Nepal, in return, would adhere to One-China Policy and would not allow any force in Nepal to engage in anti-China activities, including pro-Tibetan independence activists (Lohani, 2010). Such understanding between these two nations is the reason why Tibetan refugees in Nepal are excluded from any discourse around human rights such as freedom of opinion, expression and peaceful assembly, celebration of their culture and religion. In addition, the Nepalese authorities have taken a pro-China posture of closely monitoring and suppressing what possibly are Tibetan sentiments that arise from the Tibetans in Nepal from time to time. In addition, sadly, any sentiment by the Tibetan people in Nepal is construed as an anti-Chinese activity. Certainly, Nepal has been successful in leveraging their geopolitical position from this Asian giant through economic rewards continuously offered to the Nepalese government via trade assistance, tourism improvements, investments and other development projects in recent years.

\section{Buddhism, Asian Values and Democracy}

It is interesting to see how Tibetans live in their settlements. Whether it is in Nepal or in Majnu Ka Tilla in Delhi, the inhabitants keep their surroundings clean. By six in the morning, they are up and running and humming. They water the footpaths, sweep them voluntarily with brooms and keep their environment clean without any need for the workers of civic authorities to take care of. Their conscientiousness and civic sense is unparalleled. A communitarian outlook and caring they attribute to the Buddhist principles of caring for individuals and communities and about human interaction within the larger environment including all life forms of flora and fauna. These values have entered into their businesses too. Tibetan commerce spreads its limited prosperity along to other Tibetan communities in all directions of the Indian subcontinent and beyond. One does not see a resigned weariness of the refugee existence in these settlements. The transformation is not limited to the impressive new buildings that have sprung up in Majnu Ka Tilla. We see the transformation is one of change in the attitudes of the Tibetan people. These settlements today are beehives of industry, energy and enterprise, all laced by an attitude, which seems to suggest that these people are resilient. Today these settlements also use their limited space for tourism and allow western tourists to walk through the crowded lanes in Boudhhanath in Kathmandu, McLeod Ganj in Dharmshala and Majnu Ka Tilla in Delhi.

There have been some suggestions in the literature about the nature of Dalai Lama doctrines and documents such as the constitution made for the government in exile that it is inspired by western elements (Frenchette, 2007). Dalai Lama rejects such notions that the Tibetan exile government is western inspired and instead he argues:

The Buddha proclaimed that each individual is a master of his or her own destiny, highlighting the capacity that each person has to attain enlightenment. In this sense, the Buddhist worldview recognizes the fundamental sameness of all human beings. Like Buddhism, modern democracy is based on the principle that all human beings are essentially equal, and that each of us has an equal right to life, liberty, and happiness.... While it is true that no system of government is perfect, democracy is the closest to our essential human nature and allows us the greatest opportunity to cultivate a sense of universal responsibility.... Some Asian leaders say that democracy and the freedoms that have come with it are exclusive products of Western civilizations.... I do 
not share this viewpoint (cited in Frechette, 2007: 113).

Ever since Tibetan people have opted for refuge in other countries, their main political goal has been the independence of Tibet. After five decades in exile, Tibetan people are now scattered in many parts of the world, primarily in India, Nepal, United States, Switzerland and many other western nations. With the changing adaptation, the Tibetan refugees have taken advantage of the host nations' culture, opportunities and facilities. Even Dalai Lama has encouraged Tibetans to move to new locations mainly in western countries. Conway (1975) believes that such an outlook from Dalai Lama, himself has two major advantages "first, it will ensure that the Tibetan refugee community as a whole remains intact, gathered in sufficiently large groups to be able to maintain their own language and religion" (Conway, 1975:76). With Tibetans teaching their own language in schools, they have opportunity to maintain the essentials of their rich heritage. Second, "such a policy advantages the economic support and will prevent the Tibetans from becoming a depressed and dependent minority, existing solely from the handouts of a world community, which might so easily forget them, or ignore them in favour of more pressing claims elsewhere" ( Conway, 1975 : 76).

The most significant change observed in the Tibetan community due to the foreign cultural adaptation is the introduction of democracy in the political structure of Tibetan exile administration and the changing determinants of independence. This perceived change in the traditionally considered feudal social fabric of Tibetans becomes amply clear when we hear what Dalai Lama said in 1987. Addressing the US Congressional Human Rights Caucus in Washington, the Dalai Lama spelt out his fivepoint peace plan for Tibet. In this he contemplated: the creation of a zone of peace and ahimsa (non-violence) covering the entire Tibetan ethnic area (which would include the present Tibet Autonomous Region as well as the erstwhile Tibetan provinces of Amdo and
Kham); the abandonment of China's policy of population transfer (Han people moving into Tibet); fundamental human rights, democratic and electoral freedoms for the Tibetans; denuclearisation of Tibet and protection of its natural environment; finally, the commencement of earnest negotiations to determine the future status of Tibet. In subsequent statements at Strasbourg the following year, and later, the Dalai Lama clarified the last point: he was seeking "genuine autonomy: for Tibet within the ambit of the Chinese state, not independence, since his principle concern was survival of the Tibetan culture, religion and way of life" (Bhoothalingam, 2007: 3384).

The Tibetan intellectual scholarship and its leadership certainly took the advantages that came with the formation of an exile government in Dharmshala in India. These advantages, we argue, increased opportunities through to increased exposure to English informed education as available in India; to western contact via India; and many scholarships and grants that the Tibetan youths could receive particularly from Indian, American and also western nations. Consequently, the Tibetan youths continue to remain sensitive to their core traditional Buddhism while making the best possible examination of the growing western liberalism and in having an opportunity to appreciate the intrinsic additional value of the western thought to the Tibetan democratic precipice. However, the Western scholarship of growth of Tibetan democracy appears to overestimate the influence of western liberalism on Tibetan democracy and we posit that such views may be due to reviewing Tibetan democratic principles against the backdrop of the PRC ideologies. The PRC has its ideological position on Tibet's inalienability from the Chinese nation-state with while the Tibetan Government in Lhasa regards Tibet as an independent polity.

Paradoxically, Tibetan culture and Chinese state ideology both link religion to national identity, the foundation on which their conflict rests. 
The state calls for religion and patriotism towards China to be intertwined, a condition that did not apply in pre-modern Tibet. The PRC policies consider the religious element in Tibetan culture in strategic terms, with a main battlefield, a target in the form of religious influence, and a goal of reducing the negative effects of religion on the region's development and stability. PRC names the Dalai Lama as a malefactor, destructive not only to national unity but also to Tibetan Buddhism itself-a portrayal deeply resented by the Tibetans (Cooke, 2007: 6). Such official statements, which bind the goal of "building socialist spiritual civilisation" with the anti-separatist struggle and religion's negative influence, implicate religion and its management by the state in the wider goal of nation-building through social re-engineering, a process to be effected both from within religious circles and society at large (Cooke, 2007: 6) .

We see that the Tibetan exiles are in a democratic transition, as they have embraced democracy as a normative ideal towards which they are reforming their political system (Frenchette, 2007: 98). It is said that when democracy was first introduced among the Tibetan exiles during the 1960s, it was interpreted as a gift that "enlightened" political leaders gave "from above" (Frenchette, 2007: 98). Since the establishment of the Tibetan exile administration, the Dalai Lama has publicly advocated the development of democracy. He proposed that Tibet should be restructured as a democracy, and, at the same time, he initiated a series of experiments with democracy in exile, both to prepare the Tibetans for a return to Tibet and to facilitate the exile administration's claims to legitimate governance of Tibet in international contexts (Frenchette, 2007).

Whatever the source is for Tibetan democracy in exile, but it has certainly ascertained the drawback of past Tibetan political structure before exile. Ganguly (2001: 11) notes that although Dalai Lama's "government in exile is a democracy; he has admitted that the feudal system he left behind in Tibet was unjust and exploitative".

Although democracy is being practiced in Tibetan exile government, but more than the power of democracy, Tibetans have faith in the holy power of the Dalai Lama in giving Tibet its freedom and independence. Tibetan belief establishes the Dalai Lama as "uniquely capable of supreme governance. As manifestations of the bodhisattva of compassion, called Chenrezig in Tibetan, they are superior beings who are capable of seeing the past, present and future within multiple realms of existence, and unlike normal beings, capable of choosing where to be reborn" (Frechette, 2007: 107). Ganguly (2001: 13) in her treatise highlights her conversation with one watery-eyed vegetable seller in Dharmshala who says, "[t]he Dalai Lama will lead us to freedom... if not the fourteenth Dalai Lama, then the fifteenth, or the sixteenth, or the one after that". The above assertion is even corroborated by the young Tibetans in Nepal. A 19-year-old Tibetan woman said:

I do not understand what democracy is all about. We are not living in our land. However, my parents say that we need to be prepared for independence of Tibet. My mother says only the Dalai Lama can bring us our freedom. For us, Dalai Lama is a god. I do not know about his power because I have never met him and I understand very less Tibetan language. My uncle says that Dalai Lama, when gives speeches in Tibetan language, then only people would understand his power. According to my uncle, Dalai Lama has the ability to make us stand together and tell us where we are destined. In addition, now I feel, after every generation we are losing Tibetan culture. For example, whenever I speak, I use three languages: all at a time, Nepali, English and Tibetan. However, one thing is sure, we Tibetans are such religiously made that as long as Dalai Lama is there, and we will not really forget Tibet. 
In Kathmandu, the capital city, there are two Tibetan camps, one in Jorpati and another in Jawalakhel in addition to the Tibetan refugee reception centre in the suburb of Ekantakuna. Interviews for this research were primarily conducted in these two areas.

An adult Tibetan woman who was selling 'Khapse', an ethnic Tibetan delicacy during Buddha Jayanti (25th May, 2013) nearby Boudhhanath Stupa says,

I was born in Nepal and I do not even remember when my grandparents came here. I have never been to Dharmshala. However, someday I want to go just only to see Dalai Lama and Tibetan government there. Actually, I do not really know about our government too because I have not seen them nor have I received anything so far. I have been struggling on my own by selling Khapse and other Tibetan products in roads and busy markets. Nevertheless, I worship Dalai Lama. I have kept his photo in my room. When I see him, it gives me positive vibe. I can feel the Tibet, which I have never seen. My heart becomes heavy sometimes.

Likewise, a human rights activist closely working with Tibetan community in Nepal says,

In my opinion, the Tibetan community in Nepal has far well-developed their understanding about the importance of democracy and what democracy can do to change the autocratic regimes. This is because of their encounter with the Nepalese political development. Nepalese Tibetans have seen the changing politics of Nepal from Kingship to democracy in 1990, from the 1990's democracy to decade long Maoist conflict and from the peace process until the recent Federal Republic of Nepal. One of the very interesting cases they have seen is how Maoist party in Nepal has been able to fit itself in the race of democratic parties. Therefore, the talk of Tibetan democracy is important because it can possibly give
China insights to adopt democratic values to some extent. Again, since Tibetan democracy has its foundation on the strong faith over Dalai Lama, I personally feel that the Tibetan campaign will get more complex and hard in his absence.

Within the exiled Tibetan community as well, including many who live in the northern Indian city of Dharmshala, the unofficial capital of the Tibetan government-in-exile significant observations and debate over the issue of using violence or non-violence has been recorded in the last ten years or so (Ganguly 2001). Though the Dalai Lama and his officials have long been criticised for the use of nonviolence as a tactic and have chosen to embrace non-violence and peaceful struggle and passive resistance as viable alternatives, many younger Tibetans who have grown up in diaspora have also been openly questioning this policy. Ganguly (2001) in her interviews, in the pubs of Dharmshala wrote that the young men wistfully talked of violent resistance. One of them said that he wanted to go and blow up few bridges. "Even if it doesn't bring them freedom, at least as young men they would have hurt the Chinese" (Ganguly, 2001: 17). It is true that some of the young Tibetans are growing tired of pacifism. There is fear that in the long run if such attitudes keep growing, the young Tibetans may not subscribe to the non-violence path led by the Dalai Lama to mark their return to Tibet. A 17-year-old Tulsi Gurung participated in the Special International Tibet Support Groups meeting, held at Dharmshala, India in November 2012. The program was convened by Core Group for Tibetan cause-India and facilitated by the Department of Information and International Relations, Central Tibetan Administration. This 17-year-old boy, who resides in Nepal shares stories of his Tibetan friends some of whom do talk about selfimmolation and violent protests as the only way-out.

I have many Tibetan friends. We sometimes party together during Friday nights. They are actually very kind and 
nice people. They have good sense of humour. However, when it comes to Tibetan issues I have seen them getting too aggressive and angry. They prefer wearing 'Free Tibet' T-shirts but Nepalese police have made restrictions. More and more alcohol makes them more and more arrogant and volatile. I have seen them abusing the Nepali police and Chinese government with whatever slang words that come in their mouth during party. Few of them even say that they could even self-immolate themselves if the time demands. They are in fact very impatient when it comes to getting back to Tibet. However, they also share that they have profound respect for Dalai Lama.

Likewise, Nepalese government has been suppressing Tibetan community in Nepal by not allowing basic human rights. Sonali Yangzom shares her pain:

Nepalese government and security forces are very strict these days. We cannot wear T-shirts like 'Free Tibet', 'I love Tibet' etc. In Bouddha, a few of my friends have also received beatings from thugs (we suspect them as Chinese spies). In addition, police forces take us to custody without any reasons. Even I have been into custody once when I was in class nine, the day we participated in Free Tibet Rally in front of the Chinese Embassy. During Buddhist festivals and occasions, huge numbers of Nepalese police come to our residential areas. Our right to speech, freedom to assemble and celebrate our culture have been curtailed.

We believe that the locus of the Tibetan democracy and independence lies in the faith of Tibetan people upon His Holiness the Dalai Lama. The entire hope is centred upon his philosophy, power and direction. Buddhism as the religion is the source for their political and spiritual struggle and Dalai Lama as their caretaker.
In an interview with the first author, Tseten Dhondup, born in Nepal, who is 32 years old, and a peace-loving Buddhist summarises his hope for peace and Tibetan solution as follows:

Yeah.... I think we might get a chance to see my Tibet before I die...."

This interview also confirmed that he has children and when he devotes time for the Tibetan cause, he is actually working for his children so that one day they can see a free Tibet.

\section{Karma, Suffering and Future Aspiration}

Both in Buddhism and in Hinduism the concept of 'Karma' embodies people's philosophical and spiritual outlook towards life. Karma in Buddhism, connotes both action and effects (Goose, 2007), not very different from Hinduism, although one finds an average Tibetan a greater adherer to Karma and deliberately attempting to change the course of his Karma for greater good. In popular understanding, it means the fruit of our life depends upon the nature of actions that we undertake. It is a tribute to the Tibetan elders that even the many young Tibetan youngsters in Kathmandu behold and subscribe to such views. Likewise, suffering, in Buddhism, comes from actions. Freedom from suffering, it is said is inevitable. Dalai Lama has always been portrayed as the source of 'hope' and 'resilience' in the theocratic life of Tibetan people to take people from the journey of sufferings towards happiness. Dalai Lama's effort to consolidate Tibetan democracy is being considered as a precious gift for the Tibetan people. Our journey through the research process took an analytical break at this point to stop and reflect on an earlier rhetorical memo that the first author wrote a while ago reflecting on the suffering and on Dalai Lama, recalled what Kathy Charmaz wrote originally in 2006.

Suffering is a moral status as well as a physical experience. A moral status confers relative human worth and thus, measures deserved value or devaluation. Stories of suffering, reflect, 
redefine, or resist such moral status.... Suffering can award an individual an elevated, even sacred, moral status. This is someone who has been in sacred places, who has seen and known what ordinary mortals have not. His or her stories are greeted with awe and wonder. (Charmaz, 2006: 77-79)

It is appropriate to utilise an earliest memo of the first author that offers a description to Dalai Lama in the context of the concept of suffering.

Show me one man that has walked on this earth and is amidst us still that is an embodiment of resilience and hope together? It is a pure joy to see him. It is not easy for him to put his past. Yet when he cried as he did. It is not for himself it is for his people' Admittedly the entire people of Tibet-at least those who live beyond Tibet and those that live overseas have transformed themselves to ahimsa, nonviolence-an approach not liked by the leaders in mainland China. He is an inspiration to peace and this inspiration resounds in millions of refugees not just Tibetans around the world.

\section{The Dalai Lama Phenomenon}

The currently revered spiritual leader of the Tibetan people, the 14th Dalai Lama was born Lhamo Dhondup on 6 July 1935 to a farming family in the village of Taktser in North-Eastern Tibet. At the age of two, he was recognised as the 14th reincarnation of the 13th Dalai Lama, Thubten Gyatso. On 22 October 1940, he was formally enthroned at a ceremony in the Potala Palace, Lhasa, Tibet. As Buddhism offers liberation from suffering, democracy will provide the Tibetan people the means to attain freedom from injustice (Administration, 2013). This is their belief and their longing of a people that are violated culturally and leading to immolations and frenzy. One cannot gaze into crystal ball and say what future lies for these people, but as each day when sun rises around Boudhhanath Stupa, one would notice many beggars and even mendicants to continue to sit in the streets. One would also continue to see street vendors selling clothes, vegetables, etc. while keeping the surroundings clean and immaculate. People taking morning walks around the stupa would still be a sight. Even today, the crowd and their activities are worth a silent watch as they rekindle with piety the feelings of 'peace' and 'joy' that reverberate from the stupa atmosphere. Amidst all these happenings there are interesting and contrasting things to watch and learn. According to a Nepali and non-Tibetan shop owner in Boudhhanath:

The most unique social values that Tibetans own and we (Nepalese) lack is 'altruism' and 'community support'. The street vendors, early morning and evening around Boudhhanath, majority are Tibetan people. Many middle income Tibetans earn their living this way. However, if you are wondering who would buy their clothes and products everyday and how they are sustaining their business then the answer is simple-it is because of rich Tibetans who buy. Tibetans are so community centric that they support their community members in whatever ways possible. Not only this, if one Tibetan reaches America or any other western country, then he/she takes many others in a few years. They are very supportive in that sense, may be because they have learned from their hardship and struggles. Hinduism too teaches charity, but more than the Hindu Nepali people, it is the Tibetans who give money to beggars and even donate at different charities and on all occasions irrespective of Nepali or Tibetan cause. 'Altruism' and 'Community-Centrism' are the few important aspects of Tibetans' lives. Many Tibetans hold views that altruism can purify anyone from his/her bad karma.

A Tibetan refugee at Khampa camp says: 
We Tibetans are very conscious about the teachings of Dalai Lama. We have his photos, audio and CDs of his lectures and teachings in our rooms. When we listen to him our pain and restlessness are all gone, the vacuum within us gets erased, and hearts fulfilled with more hope.

The uniqueness of Tibetan refugees comes from their resilience, their coping and the way they see their future and the inspiration they receive from their spiritual master, the Dalai Lama. We believe it is pertinent to sprinkle a few of his teachings here to illustrate how they assist with individual and community transformation. Issues that we have chosen here have to deal with the suffering, happiness, resilience and hope as illustrated below:

You must not consider tolerance and patience to be signs of weakness. I consider them signs of strength. (Dalai Lama, 2012: 39)

From the moment of our birth, every human being wants happiness and avoids suffering. In this we are all same. (Dalai Lama, 2012: 87)

Human happiness and human satisfaction must ultimately come from within oneself. It is wrong to expect some final satisfaction to come from money or from a computer. (Dalai Lama, 2012: 104)

Whether one believes in religion or not and whether one believes in rebirth or not, there is not anyone who does not appreciate kindness and compassion. (Dalai Lama, 2012: 116)

Unlike an external enemy, the inner enemy cannot regroup and launch a comeback once it has been destroyed from within. (Dalai Lama, 2012: 119)

The main cause of depression is not lack of material necessities but deprivation of other's affection. (Dalai Lama, 2012: 137)
It is necessary to help others, not only in our prayers, but also in our daily lives. If we cannot help others, the least we can do is to desist from harming them. (Dalai Lama, 2012: 151)

His teachings have positioned the role of 'self' and 'within' at the supreme level. Dalai Lama has advocated for the inner strengths approach that needs to be awakened in order to free ourselves from sufferings. Dalai Lama's teachings direct people to shift their struggles from materialistic sufferings to spiritual wellbeing. 'Love' and 'Compassion' are so highlighted that happiness 'within' and happiness 'outside', both are fundamentals for life.

A Buddhist monk at Tibetan section office at Jorpati in conversation with the second author said:

Although due to changing culture and values, different adaption, Tibetan youngsters are seen little deviated from spiritual knowledge, but their family values and tradition are still alive. If you go to houses of Tibetan people you can see big 'temple' constructed inside the room with lots of investment. Everywhere Dalai Lama's photos, teachings are posted. Children basically learn from what they see every day, every time. They will not totally deviate from Buddhist culture, values and ways of life.

The elderly and the frail-aged Tibetan refugees within camps, they appear to have conceded that the Tibetan issues belong to the young generation. As elders, they have lived their lives in hope to return to Tibet with strong belief in the teachings of Dalai Lama and Buddhism. These elderly often confess that they may not see a free Tibet and the freedom in their life. Economically, they confirm life is not difficult in Kathmandu because they have located their sources of income within the markets in Nepal and India but also in foreign and distant markets. In addition, few elderly Tibetan families receive remittances from their children who have settled abroad: Europe, Australia and 
in the USA. As one of the elders in Nepal narrated:

Free Tibet will continue to be a dream for many generations to come but remaining hopeful is the best way to lead life.

However, the younger generation thinks in different ways. They think that times have changed and the Tibetan issue must change along with the course of time. A daughter of a Tibetan refugee in Khampa camp who studies in Namgyal, a Tibetan school says:

I do not know where my future takes but I want to go to Tibet once not as a Tibetan refugee but as a professional. It is difficult for Tibetans to study technical subjects here in Nepal for so many reasons. Therefore, I am planning to go to India where I can study with scholarship. My school sends good Tibetan students to India for technical studies. In my school, thrice a week, political discussions are organised among students regarding Tibetan issues. However, I rarely participate. That does not mean I do not like Tibetan issues, I do. Nevertheless, I believe for children it is time to study and read new things. There are so many things to learn and discuss.

While it is a fact that Tibetan modernism is currently shaping under global influence, it is absurd to think that western thought has influenced to make the Tibetan spirituality more compassionate and non-violent. Karuna (compassion) and ahimsa (non-violence) are the two main tenets of spiritual master the Buddha.

\section{Carpet and Livelihood}

With the advent of carpet production within Tibetan camps in Nepal during the 1960s, the entire livelihood aspects of the Tibetan refugees received sustenance. The carpet weaving appears to have become "the basis for an assertion of cultural and political autonomy in exile" (O'Neill, 2005: 275). In the last four decades, the Tibetan carpet penetrated international market turning cottage industry into the major leading export industry of Nepal. It established the position of Tibetan refugee community into the centre of Nepal's economy. This carpet industry has "transformed the lives of both refugees and indigenous Tibetans living in Nepal" (O'Neill, 2005: 276). For instance, in 1995 alone, there were altogether 295 carpetweaving operations out of which 80 belonged to the Tibetan owners while 159 belonged to the local Nepalese (O'Neill, 2005). However, in recent years, many Tibetans have shut down their industries due to the decade long Maoist conflict in Nepal. One of the local shopkeepers on the main line of the Boudhhanath gate has the following to say:

Tibetan carpet made Tibetans immensely rich. Many of them are the richest businesspersons in Bouddha; even Nepali local people cannot compete their business. They made huge money because Tibetan carpets were very expensive and are still the same. A single carpet (small size) costs more than thirty thousand Nepali rupees. The carpet goes up to three to four hundred thousand or even more than that. However, during Maoist conflict, many such operations got shut down because of labour disputes. However, Tibetans have not completely left the business. The only difference between then and now is that before the 1990 Tibetan refugees used to work in the carpet industry but now they own them. Not many Tibetans work as labour in industries. At present, low caste Nepali people who are considered lower in caste hierarchy especially their children and their women work in such carpet factories. Tibetan owners just export the products in high value and earn money.

Be it Majnu Ka Tilla in Delhi that flourishes today with booming business that outsources Tibetan flags and poster making to the Punjabi basthi next door, or the Boudhhanath in Kathmandu with an ambience of piousness and 
serenity-these settlements are the hope building centres of all economic prosperity of the Tibetan community. In these uncertain times, they are also the only sources of making money. Singled out, as the number one economic activity the carpet weaving alone gave them every aspect of livelihood including food, shelter, business, security, and above all a discipline that nurtured their spiritual practice as well. Chanting and meditation while weaving improved their individual and collective psyche. Comparing stories and telling tales of the family during recess allowed them to share concerns and build compassion. Adaptation to western colours and making mosaics of Tibetan cultural and modern aesthetics and genuine partnerships with traders and governments both in Nepal and India and in international platform gave them the finesse required to progress as a community at the same time build their families. Tibetan children receive higher education, are in good health and appear to be leading a decent life. Many local Nepalese living in Boudhhanath area for generations say that Tibetans have major role in changing the economy of Bouddha area. They say that Tibetans brought the strong flavour of Buddhist religion along with them and spread it over Boudhhanath Stupa region. Previously, in their grandfathers' time, there used to be very less economic activities around Boudhhanath stupa. Now, the Stupa has become the major tourist destination. Similarly, in Majnu Ka Tilla in Delhi, India and in McLeod Ganj in Dharmshala, the Tibetans introduced new Buddhists ornaments, flags, cultural foods and strong religious beliefs, which provided new set of economic activities for people around their settlements. Just as Bouddha area has transformed rapidly into a Buddhist spot in Kathmandu surrounded with attractive tourism for ornaments, flags, restaurants, hotels, guesthouse, monasteries, Majnu Ka Tilla, gives the same cosmopolitan air of commercial activities accompanied by rigorous spiritual pursuits. In keeping with its growth, the languages in these settlements are: Tibetan, Hindi, English and Nepalese. There are restaurants that have their menu translated into Chinese.

A teenage college-going Tibetan woman talks about the Tibetan people:

Tibetan people are able to make it well through their hard work. Carpet is the primary source. Besides, Tibetans' changing lifestyle is also being reflected with the changing refugee camp atmosphere. In Jorpati's Khampa Camp, in Nepal the housing structures are changing. In Majnu Ka Tila we have impressive buildings. Many though in their refugee status are able to indulge in building modern houses.

In comparison to the local Nepalese one would find that the Tibetan live better than the local people and it is also our observation that their lifestyle is related to their enterprise and cultural factors. Despite their political status within Nepalese society as refugees they do not lag behind economically and have demonstrated capacity to even employ coreligionists from Nepal and continue to assist Nepal and its economy every way, similar to the outsourcing to the inhabitants of the Punjabi basthi in Delhi.

\section{Conclusion}

From this research, it is clear that Tibetans around the world do not know their future nor do they appear unduly worried. Most of them appear resilient and hopeful to see a 'free Tibet' a dream closer to their hearts, someday in the future. Thus, in this research, after examining their deep association between the philosophy of life based on the principles of 'karma' and their everyday economic avocation of weaving 'carpets', we unfold that these people weave their lives around karma and the carpets. Karma embodies their philosophical and spiritual outlook while carpets, mats and paintings symbolise their day-to-day struggles, enterprises to cope, survive, thrive and flourish. Hence, the 'karma carpet' symbolises their journey into the future. However, it is ironical to note that the Tibetans although a refugee group do not enjoy the same rights and 
privileges in Nepal, when compared to other refugees living in the world decreed under the United Nations Conventions.

Finally, we wish to end this article with two short quotes. The first one is an excerpt from a poem:

I have an aim that some day

Our children will stand atop the plateau of a free Tibet

In addition, wash away the ravages the Chinese left behind

(Tsoltim N. Shakabpa - 2011)

The second is a self-explanatory quote from the website of Majnu Ka Tila

It reads:

The young all have the same dream: to free Tibet. Some quickly forget this dream, convinced that there are some important things to do, like having a family, earning money, career, etc. Others, though, decide that it really is possible to make a difference in society and to shape the Nation we will hand on to future generations.

\section{About the Authors}

Dr. Venkat Pulla, PhD is a Tata Dorabji Merit scholar from the Tata Institute of Social Sciences, India. Formerly, Foundation Head of the Department of Social Work, Northern Territory University, Darwin, Australia, Venkat also taught social work at the Charles Sturt University and is currently Senior Lecturer, University of the Sunshine Coast, Queensland, Australia. His research interests are in human coping and resilience, spirituality, green social work and strengths approach to social work. He has founded the Brisbane Institute of Strengths Based Practice. He has co-edited papers in Strengths Based Practice, Allied Publishers, 2012; and Perspectives on Coping and Resilience, Authors Press Global Network, 2013.

Kanchan Prasad Kharel has obtained his Bachelors in Social Work and Masters in Development Studies from the Kathmandu
University with distinction. He is currently working as Secretary General YUWA and Director of Center for Youth Studies (CYS). He works with youth and relates their issues to the bigger development agendas. He is a social activist and critic of development issues and process. Kanchan is an activist worker of Amnesty International Nepal, Kathmandu Network and National Human Rights Foundation.

\section{References}

Administration, T. O. (2013). Kashag's

Statement on 52nd Tibetan Democracy Day. ( $T$. Jamchhen, Ed.) Tibetan Bulletin, 16 (3), 6

Aryal, D., Subedi, R. P. and Thapa, S. (2010).

Diplomatic Dealings, Kathmandu: Variety Press

Bentz, A. S. (2012). Being a Tibetan Refugee in India, Refugee Survey Quarterly, 31 (1), 80-107

Bonnano, G. A. (2004). Loss, Trauma and Human Resilience: How We Underestimated the Human Capacity to Survive after Extremely Aversive Events, American Psychologist, 59(1), 20-28

Bhoothalingam, R. (2007). For a 'Harmonious Resolution' of the Tibetan Question, Economic and Political Weekly, 42 (33), 3383-3387

Bureau of His Holiness The Dalai Lama. (2012). The Dalai Lama, An Ocean of Compassion, New Delhi: Hay House Publishers (India) Pvt. Ltd

Bureau of Democracy, Human Rights and Labor, United States Department of State-Diplomacy in Action, available at:

http://www.state.gov/j/drl/ (accessed 03 October 2013)

Conway, J. S. (1975). The Tibetan Community in Exile, Pacific Affairs, 48 (1), 74-86

Cooke, S. (2007). Merging Tibetan Culture into the Chinese Economic Fast Lane, China

Perspectives [Online], 50 | November-

December 2003, online since 19 April 2007, available at:

http://chinaperspectives.revues.org/775

(accessed 08 January 2014)

Country Reports on Human Rights Practices for 2012, Embassy of the United States, 
Kathmandu, Nepal, available at:

http://www.state.gov/documents/organization /204619.pdf (accessed 29 May 2013)

Frechette, A. (2007). Democracy and Democratization among Tibetans in Exile, The Journal of Asian Studies, 66 (1), 97-127

Ganguly, M. (2001). Generation Exile, Transition, 87, 4-25, available at: http://muse.jhu.edu.ezproxy.csu.edu.au/journa Is/transition/v010/10.3ganguly.html(accessed 11 January 2014)

Ghose, L. (2007). "Karma" and the Possibility of Purification: An Ethical and Psychological Analysis of the Doctrine of "Karma" in Buddhism, Journal of Religious Ethics, 35 (3), 259-289

Hamal, Y. B. (2010). Ecology of Nepal's Foreign Policy, Varanasi: Kabra offset

Kharel, B. P., Siwakoti, G.K. and Sharma, G. Bandi, available at: http://www.thehimalayantimes.com/fullNews. php?headline=Monk's+hushhush+cremation+sl ammed\&NewsID=371254 (accessed 11 January 2014)

Lohani, M. (2010). Nepal-China Relation. In S. K. Bhattarai (ed.) International Relations and Foreign Affairs, Kathmandu: Makalu Publication House, p. 430

Majnu Ka Tilla, available at: http://www.majnukatilla.com/majnu-katilla.html (accessed 11 January 2014)

O'Neill, T. (2005). Ethnic Identity and Instrumentality in Tibeto-Nepalese Carpet Production, Asian Studies Review, 29, 275-286
O'Neill, T. (1999). The Lives of the TibetoNepalese Carpet, Journal of Material Culture, 21-38

Tamang, G. (2013, May 28). Tibetan Cases of Self-Immolation, An Interview with K. P. Kharel, the second author

Pulla, V. (2013a). Coping and Resilience: Peoples Innovative Solutions, International Journal of Innovation, Creativity and Change, 1(1), 1-9, available at: www.ijicc.net (accessed 11 January 2014)

Pulla, V. (2013b). Spiritually Sensitive Social Work: The Road Worth Taking, Wagga Wagga, Charles Stuart University

Shakabpa, N. T. (2011). 'I Have an Aim and a Target', Anthology of Tibetan, Mongolian and Uyghur Poetry and Writing, available at: http://100tpcfreetibet.weebly.com/poems.htm I (accessed 08 January 2014)

Tibetan, 16, Burns Himself to Death. (2012, December 11). Republica, p. 6

Tibetan Tying Self-immolation Dies. (2013, February 15). Republica, p.3

Thinley, P. (2010, December 4). Planning Commission Releases Report on Tibetan Demographic Survey, Phayul, available at: http://www.phayul.com/news/article.aspx?id1/4 28666\&t $1 \frac{1}{40}$ (accessed 15 June 2011)

Woodcock, G. (1970). Tibetan Refugees in a Decade of Exile, Pacific Affairs, 43 (3), 410-420 Wong, E., (2013, April 15). China Curbs Flow of Tibetans into Nepal, International Herald Tribune, p. 3 